\title{
Lick rates in rats exposed to gamma-irradiation'
}

ROBERT W. SCHAEFFER AND JAMES C. SMITH

FLORIDA STATE UNIVERSITY

Lick rates in male rats were measured before, during, and after irradiation with $100 \mathrm{r}$ gamma rays. No alterations in the licking reflex were found. These results were interpreted as further evidence that classically conditioned saccharin aversion is not attributable to prompt neural alterations.

Classical conditioned saccharin aversion, following a single simultaneous pairing of ionizing radiation and saccharin ingestion, is a well established behavioral reaction in rats (Garcia et al, 1961; Kimeldorf \& Hunt, 1965). The systemic physiological concomitants produced by irradiation which are responsible for eliciting this aversion are not presently understood, but previous studies have shown that the onset of irradiation is accompanied by (1) increased heart rate (Hunt \& Kimeldorf, 1962), (2) EEG desynchronization (Cooper \& Kimeldorf, 1964), (3) behavioral changes (Hunt \& Kimeldorf, 1962; Dinc \& Smith, 1966), (4) alterations in olfactory bulb neuron activity (Cooper \& Kimeldorf, 1966), and (5) changes in electrical activity in the visual system (Smith \& Kimeldorf, 1964). In addition, gastrointestinal dysfunction and emesis has been shown to accompany and follow exposure to ionizing radiation (Kimeldorf \& Hunt, 1965). Further evidence for the effects of radiation on neural tissue has been presented in Soviet reports of altered reflexive behaviors in irradiated rabbits (cf., Kimeldorf \& Hunt, 1965).

Previous studies have established that licking in the rat is a reflexive behavior, since mean lick rate in rats is a constant 6-7 per sec., independently of age, sex, deprivation level, and type of fluid consumed (Stellar \& Hill, 1952; Schaeffer \& Premack, 1961).

If ionizing radiation does directly alter neural tissue and reflexive behavior, as suggested above, conditioned saccharin aversion might be explicable on the basis of some interaction of saccharin ingestion and radiation produced alterations in the licking reflex. To test for this possibility, the present study was designed.

\section{Method}

The Ss were five male Sprague-Dawley rats, about 120 days old at the beginning of the experiment. They were individually housed in Hoeltge HB-11 cages, and ad lib food maintained throughout the entire experiment.

The gamma radiation source was an Atomic Energy of Canada Model 150C Gamma-beam Irradiator containing 1553 Curies of $\mathrm{Co}^{60}$. The Ss were irradiated in their home cages at a dose rate of $1.3 \mathrm{r} / \mathrm{min}$. for $76 \mathrm{~min}$., with an approximate total dose of $100 \mathrm{r}$. Lick rates were measured by drinkometers and recorded by an Esterline Angus digital recorder on tape moving at $1.9 \mathrm{~cm} / \mathrm{sec}$.

All Ss were originally ad lib maintained on water for four weeks, then $23 \mathrm{hr}$. water deprived and presented with a $0.1 \%$ saccharin solution for $76 \mathrm{~min}$. daily for four consecutive days, with $23 \mathrm{hr}$. intervening between each successive saccharin presentation. Procedurally, the first saccharin presentation constituted a sham exposure, and the third and fourth saccharin presentations were equivalent to the typical postirradiation saccharin preference tests (cf., Smith \& Schaeffer, 1966). The gamma irradiation coincided with the second saccharin presentation.

\section{Results and Discussion}

Momentary lick rates were determined for each $\mathrm{S}$, sec. by sec., throughout each of the four saccharin test periods. The mean lick rate and lick rate range for each $S$ within each test period are presented in Table 1. As is evident from these data, the mean lick rates and lick rate ranges obtained during irradiation and in the two post-irradiation test periods did not differ from the rates that were recorded in the preirradiation test. Furthermore, neither the lick rate ranges nor the mean lick rates obtained in the present study differ from lick rates previously reported for nonirradiated rats tested under a variety of experimental

Table 1. Mean lick rates and lick ranges for $0.1 \%$ saccharin solution before, during, and following gamma irradiation. Mean lick rates represent the average lick rate per sec. within each session. The range values represent extreme momentary lick rates found for each $S$.

$$
\text { Test Condition }
$$

\begin{tabular}{ccccccccr} 
& \multicolumn{2}{c}{$\begin{array}{c}\text { Before } \\
\text { Irradiation }\end{array}$} & \multicolumn{2}{c}{$\begin{array}{c}\text { During } \\
\text { Irradiation }\end{array}$} & \multicolumn{2}{c}{$\begin{array}{c}\text { Post-Irradiation } \\
\text { Test 1 }\end{array}$} & \multicolumn{2}{c}{$\begin{array}{c}\text { Post-Irradiation } \\
\text { Test 2 }\end{array}$} \\
\hline \multicolumn{2}{c}{ Mean Rate } & Range & Mean Rate & Range & Mean Rate & Range & Mean Rate & Range \\
\hline S1 & 6.5 & $5.5-7.0$ & 6.6 & $6.0-7.5$ & 6.4 & $5.0-7.5$ & 6.7 & $6.0-7.5$ \\
S2 & 6.3 & $5.5-8.0$ & 6.0 & $5.5-6.5$ & 6.2 & $5.5-7.0$ & 6.5 & $6.0-7.5$ \\
S3 & 6.7 & $5.5-7.5$ & 6.8 & $6.0-7.5$ & 6.8 & $6.0-8.0$ & 6.6 & $5.5-7.5$ \\
S4 & 6.6 & $5.0-7.5$ & 6.5 & $5.5-7.0$ & 6.7 & $6.0-8.0$ & 6.7 & $6.0-8.0$ \\
S5 & 6.2 & $6.0-7.5$ & 6.3 & $5.5-7.5$ & 6.2 & $5.0-7.0$ & 6.3 & $5.5-7.5$ \\
\hline
\end{tabular}


conditions (Stellar \& Hill, 1952; Schaeffer \& Premack, 1961).

The physiological and behavioral data summarized by Kimeldorf \& Hunt (1965) leave no doubt that animals can detect the presence of ionizing radiation, or that ionizing radiation, as a stimulus, has a direct, immediate effect upon behavioral and neural activity. Conditioned saccharin aversion cannot be explained on the basis of prompt neural stimulation, however, since the aversion has been obtained with radiation dose rates much lower than those thus far required to produce behavioral arousal and neural activation (Garcia et al, 1961), and in rats that were deeply anesthetized during the irradiation period (Hunt \& Kimeldorf, 1965). The present finding that the licking reflex was unaffected by a radiation dose equivalent to ten times the minimum dose required to produce the aversion (cf., Garcia et al, 1961, p. 385) also argues against a prompt neurological reaction as an explanation for the aversion. Further evidence against a prompt neural stimulation explanation of the aversion was reported by Smith \& Schaeffer (1966) in a study which followed the time course of the development of the aversion and demonstrated that the aversion was not instantaneous, but required as long as $40 \mathrm{~min}$. to completely develop.

Garcia et al (1961) proposed that the aversion might be attributable to a radiation produced humoral motivating factor. Hunt, Carroll, \& Kimeldorf (1965) obtained evidence supporting this proposal, by showing that the non-irradiated partner in skin-vascular anastamosed parabiont rat pairs developed the aversion if it ingested saccharin shortly after its partner was irradiated. Although identification of this humoral factor has yet to be accomplished, the bulk of evidence currently available indicates that the conditioned saccharin aversion cannot be attributed to prompt neural reactions or alterations.

\section{References}

Cooper, G. P., \& Kimeldorf, D. J. Electroencephalographic desynchronization in irradiated rats with transected spinal cords. Science, 1966, 143, 1040-1041.

Cooper, G. P., \& Kimeldorf, D. J. The effect of X-rays on the activity of neurons in the rat olfactory bulb. Radiation Res., $1966,27,75-86$.

Dinc, Iffet, \& Smith, James C. The role of the olfactory system in the detection of ionizing radiation by the rat. Radiation Res., $1965,25,185$.

Garcia, J., Kimeldorf, D. J., \& Hunt, E. L. The use of ionizing radiation as a motivating stimulus. Psychol. Rev.. 1961, 68, 383-395.

Hunt, E. L., Cartoll, H. W., \& Kimeldorf, D. J. Humoral mediation of radiation-induced motivation in parabiont rats. Science, 1965 , $150,1747-1748$.

Hunt, E. L., \& Kimeldorf, D. J. Evidence for direct stimulation of the mammalian nervous system with ionizing radiation. Science. $1962,137,857-859$.

Hunt, E. L., \& Kimeldorf, D. J. Postexposure conditioning of a saccharin aversion with irradiation during deep anesthesia. Radiation Res., 1965, 25, 200.

Kimeldorf, D. J., \& Hunt, E. L. Ionizing radiation; neural function and behavior. New York: Academic P:ess, 1965.

Schaeffer, R. W., \& Premack, D. Licking rates in infant albino rats. Science, 1961, 134, 1980.

Smith, James C., \& Kimeldorf, D. J. The bioelectric response of the insect eye to beta radiation. J. Insect Physiol., 1964, 10, 839-847.

Smith, James C., \& Schaeffer, R. W. A mi nute by minute analysis of water and saccharin solution preferences following simultaneous exposure to saccharin solutions and gamma rays. Radiation Res., 1966, 27, 512 .

Stellar, E., \& Hill, J. H. The rat's rate of drinking as a function of water deprivation. J. comp. physiol. Psychol., 1952, 45, 96-102.

\section{Note}

1. Supported in part by Public Health Service Grant MH 08775 , from the National Institute of Mental Health, and Contracts At(40-1)-2903 and At-(40-1)-2690 with Division of Biology and Medicine, USAEC. 